\title{
Yellow Lake Pigments from Weld in Art: Investigating the Winsor \& Newton 19th Century Archive
}

\author{
Maria Veneno ${ }^{1}$, Paula Nabais ${ }^{2, * \mathbb{C}}$, Vanessa Otero ${ }^{2,3, * \mathbb{C}}$, Adelaide Clemente ${ }^{4}$, M. Conceição Oliveira ${ }^{5}(\mathbb{D}$ \\ and Maria João Melo ${ }^{2}$ (D) \\ 1 Department of Chemistry, Faculty of Sciences and Technology, NOVA University of Lisbon, \\ 2829-516 Caparica, Portugal; m.veneno@campus.fct.unl.pt \\ 2 LAQV-REQUIMTE and Department of Conservation and Restoration, Faculty of Sciences and Technology, \\ NOVA University of Lisbon, 2829-516 Caparica, Portugal; mjm@fct.unl.pt \\ 3 VICARTE and Department of Conservation and Restoration, Faculty of Sciences and Technology, \\ NOVA University of Lisbon, 2829-516 Caparica, Portugal \\ 4 cE3c-Centre for Ecology, Evolution and Environmental Changes, Faculdade de Ciências, \\ Universidade de Lisboa, 1749-016 Lisboa, Portugal; maclemente@fc.ul.pt \\ 5 Centro de Química Estrutural, Instituto Superior Técnico, Universidade de Lisboa, 1049-001 Lisboa, Portugal; \\ conceicao.oliveira@tecnico.ulisboa.pt \\ * Correspondence: p.nabais@campus.fct.unl.pt (P.N.); van_otero@fct.unl.pt (V.O.)
}

Citation: Veneno, M.; Nabais, P.; Otero, V.; Clemente, A.; Oliveira, M.C.; Melo, M.J. Yellow Lake Pigments from Weld in Art: Investigating the Winsor \& Newton 19th Century Archive. Heritage 2021, 4, 422-436. https://doi.org/10.3390/ heritage 4010026

Academic Editor: Diego Tamburini

Received: 1 February 2021

Accepted: 21 February 2021

Published: 25 February 2021

Publisher's Note: MDPI stays neutral with regard to jurisdictional claims in published maps and institutional affiliations.

Copyright: (C) 2021 by the authors. Licensee MDPI, Basel, Switzerland. This article is an open access article distributed under the terms and conditions of the Creative Commons Attribution (CC BY) license (https:/ / creativecommons.org/licenses/by/ $4.0 /)$.

\begin{abstract}
Weld (Reseda luteola) was one of the main sources of yellow dyes used for dyeing textiles and to prepare artists' pigments in Europe until the 19th century. For the first time, this work explores the technology of preparing weld lake pigments in the 19th century by Winsor \& Newton $(\mathrm{W} \& N)$, a renowned supplier of artists' materials. Five recipes were discovered in the W\&N 19th century Archive Database and reconstructed in the laboratory. W\&N was extracting weld in neutral and basic media, and preparing the insoluble lake by complexation with $\mathrm{Al}^{3+}$ in the form of alum $\left(\mathrm{KAl}\left(\mathrm{SO}_{4}\right)_{2} \bullet 12 \mathrm{H}_{2} \mathrm{O}\right)$ or hydrated alumina $\left(\mathrm{Al}(\mathrm{OH})_{3}\right)$. Five yellow lake pigments were successfully obtained and characterized by High-Performance Liquid Chromatography-Diode Array Detector (HPLC-DAD) and Fourier Transform Infrared Spectroscopy (FTIR). Their chromatographic profiles display as main yellows, luteolin 7-O-glucoside (Lut-7-O-glu) or both Lut-7-O-glu plus luteolin 3',7$\mathrm{O}$-glucoside (Lut-3',7-O-glu). In two of the processes, the presence of gypsum $\left(\mathrm{CaSO}_{4} \bullet 2 \mathrm{H}_{2} \mathrm{O}\right)$ was unequivocally detected by FTIR, being formed as a by-product. This work offers the first identification of weld lake pigments' characteristic infrared bands. The W\&N Database proved again to be a unique source of information on 19th-century artists' materials and their commercial preparation. The knowledge gain is essential to ensure effective conservation and authentication procedures.
\end{abstract}

Keywords: weld lake pigments; yellow lakes; luteolin; 19th century; Winsor \& Newton; conservation

\section{Introduction}

Yellow dyes were used in artworks for millennia up until the advances in modern chemistry. Reseda luteola L., or weld, was one of the most important dyes in Europe up until the 19th century, and the primary source for organic yellows [1]. These were used in the textile industry as a source of yellow and green colors and prepared as artists' pigments to create precious masterpieces [1-3].

Although weld was possibly identified in textiles from Xinjiang [4,5], in 17th-century Arraiolos carpets, Portugal [6] and in Southern Swedish painted wall hangings from the 18th-19th centuries [7], assessing its conservation condition and the causes of degradation in artworks is still in its early stages. To understand the degradation mechanisms that are in play in such complex matrices as found in our cultural heritage, it is necessary to have reference materials prepared with as much historical accuracy as possible. These are used to assess the natural evolution of these colors and simulate by accelerated ageing experiments with a limited number of variables the aging of these systems. 
Methanol:water extracts of Reseda luteola, which gave the highest flavonoid yield, have shown that the main chromophore is luteolin 7-O-glucoside (Lut-7-O-glu), followed by luteolin $3^{\prime}, 7-O-g l u c o s i d e ~(L u t-3 ', 7-O-g l u)$. Luteolin (Lut), apigenin 7-O-glucoside (Api-7$\mathrm{O}$-glu), chrysoeriol glycoside (Chry-gly), luteolin $4^{\prime}$-O-glucoside (Lut-4'-O-glu), are also found, with apigenin (Api), apigenin-6,8-di-C-glucoside (Api-6,8-C-glu), and a luteolin di-O-glucoside (Lut-di-O-glu) found in lower amounts [6,8-10]. When analyzing dyed textiles, weld is identified as the yellow used by the presence of "luteolin-type" flavonoids. In 17th-century Arraiolos carpets, the yellow historical samples analyzed with LC-MS contained primarily Lut-7-O-glu, small amounts of apigenin-6,8-di-C-glucoside, Lut-3,7-Oglu and its isomer, as well as Api-7-O-glu and Lut, see Figure 1 [6]. Moreover, for the dyed textiles from Xinjiang, the identification of Lut-7-O-glu, along with other "luteolin-type" and "apigenin-type" flavonoids, led to the proposal of the use of weld in the samples analyzed $[4,5]$.
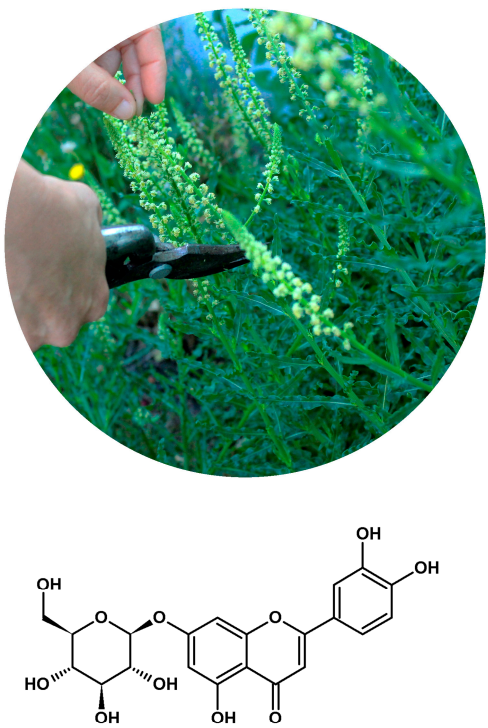

Luteolin 7-O-glucoside

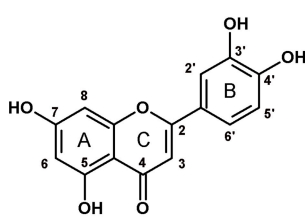

Luteolin<smiles></smiles>

Luteolin 3',7-di-O-glucoside<smiles>O=c1cc(-c2ccc(O)cc2)oc2cc(O)cc(O)c12</smiles>

Apigenin<smiles>O=c1cc(-c2ccc(O)cc2)oc2cc(OC3OC(CO)[C@H](O)[C@H](O)[C@H]3O)cc(O)c12</smiles>

Apigenin 7-O-glucoside

Figure 1. Collection of Reseda luteola in its native environment; structures for the main chromophores found in Reseda luteola yellows: luteolin, apigenin, luteolin 7-O-glucoside, luteolin 3',7-di-O-glucoside, and apigenin 7-O-glucoside.

Generally, most dyes were applied as lake pigments, formed by the colorant's precipitation with a complexing agent, such as alum, hence becoming a non-soluble pigment, in a process analogous to the mordanting of textiles [2]. Although these dye-metal complexes' exact structure is still unknown for most lake pigments, there are some proposals for luteolin-metal complexes [11-13]. Following a DFT/TDDFT study of the complexation sites of luteolin and apigenin, Amat et al. proposed that luteolin is preferentially co-precipitated or absorbed with $\mathrm{Al}^{3+}$, or other metals in a bi-dentate mode involving the 4-keto-5-hydroxy site and with a Al:Luteolin 1:1 stoichiometry [11]. The same structure was proposed by Gao et al. for luteolin- $\mathrm{Cr}$ (III) complexes, while Dong et al. proposed the same coordination sites for complexation with manganese (II), although with an Mg:Luteolin 1:2 stoichiometry, which means the existence of a complexation network is expected involving the hydroxyl groups $[12,13]$. On the other hand, Smith et al. found that the aluminium ion-flavonoids complexes (present in dyed textiles and lake pigments) prevent the natural efficient and non-degradative dissipation of excitation energy by an intermolecular proton transfer involving the $5-\mathrm{OH}$ and the $4=\mathrm{O}$ groups, hence are more susceptible to degradation [14].

Within an interdisciplinary team of chemists, botanists, and heritage scientists, with 20 years of experience in studying and retrieving the "lost knowledge" on natural dyes found in historical documents and artworks [15-19], this work will be the first step of a 
systematic study on the technology used in the past to produce weld lake pigments. For this first approach, we investigated recipes found in the Winsor \& Newton (W\&N) 19th century Archive Database, a unique primary documentary source covering handwritten formulation instructions and workshop notes of a leading artists' colormen that supplied prominent painters. The W\&N Archive Database comprises a summary index-linked to digitalized page-images of 85 manuscript books (corresponding to 15.003 database records) and a digital collection of $47 \mathrm{~W} \& \mathrm{~N}$ 19th-century trade and retail catalogues [20-22].

In a time of chemical development, especially of artificial dyestuffs, it is very interesting to note that $W \& N$ was producing at an industrial scale and selling natural yellow lake pigments during the 19th century [23]. In previous studies, we have proven that W\&N was committed to primarily selling the most high-quality and durable products $[18,24,25]$. More importantly, we have demonstrated that research on the W\&N Database enables pigment reconstructions with as much historical accuracy as possible. These references will be fundamental to advance analytical methodologies on the identification of weld lake pigments in artworks. In this work, for the first time, we disclose the infrared bands of weld lake pigments, complemented by their chromatographic profiles.

\section{Materials and Methods}

\subsection{Materials}

All solvents used were HPLC grade. For all chromatographic studies as well as dye extraction, Millipore ultrapure water was used. Luteolin $\left(\mathrm{C}_{15} \mathrm{H}_{10} \mathrm{O}_{6}\right)$, luteolin-7-Oglucoside $\left(\mathrm{C}_{21} \mathrm{H}_{20} \mathrm{O}_{11}\right)$ and luteolin-3',7-di-Oglucoside $\left(\mathrm{C}_{27} \mathrm{H}_{30} \mathrm{O}_{16}\right)$ analytical standards were purchased from Extrasynthese ${ }^{\circledR}$. Potassium aluminium sulfate $\left(\mathrm{AlK}\left(\mathrm{SO}_{4}\right)_{2} \cdot 12 \mathrm{H}_{2} \mathrm{O}\right)$, potassium bicarbonate $\left(\mathrm{KHCO}_{3}\right)$, sodium borate $\left(\mathrm{Na}_{2} \mathrm{~B}_{4} \mathrm{O}_{7} \cdot 10 \mathrm{H}_{2} \mathrm{O}\right)$, calcium carbonate $\left(\mathrm{CaCO}_{3}\right)$, and hydrated alumina $\left(\mathrm{Al}(\mathrm{OH})_{3}\right)$, were purchased from Sigma-Aldrich ${ }^{\circledR}$, while potassium carbonate $\left(\mathrm{K}_{2} \mathrm{CO}_{3}\right)$ was purchased from Merck ${ }^{\circledR}$. Gum arabic to prepare paint references was purchased in pieces from Kremer Pigmente ${ }^{\circledR}$.

Flowering branches of Reseda luteola were collected in June 2020 by A. Clemente, from wild populations near Bucelas, north of Lisbon, Portugal ( $\left.38^{\circ} 54^{\prime} 21^{\prime \prime} \mathrm{N}-9^{\circ} 6^{\prime} 30^{\prime \prime} \mathrm{W}\right)$. The plant material was spread in a tray and air-dried in the dark, in a ventilated area at $20{ }^{\circ} \mathrm{C}$.

\subsection{Synthesis Methods for Weld Lake Pigments}

Research on the W\&N 19th century Archive Database was carried out under the sub-topic weld, which resulted in 12 database records. Among these, it was possible to identify seven records for the production of weld lake pigments, however, there are only five recipes as 3 of the records are copies, see Table 1 . The remaining five database records include two notes on weld, two experiments to extract weld, and one recipe to prepare Yellow Carmine from weld, Persian berries and quercitron bark. The transcription of the production records used in this work may be consulted in Table S1, and the synthesis methods reproduced are described in Table 1. Interpretation of the materials used was based on our previous works $[18,24,25]$, which allowed us to infer that the term 'whiting' used in the recipe Yellow from Weld corresponds to calcium carbonate $\left(\mathrm{CaCO}_{3}\right)$, 'Sub. Carb.

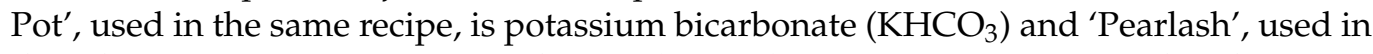
the other recipes, is potassium carbonate $\left(\mathrm{K}_{2} \mathrm{CO}_{3}\right)$. It is important to note that the recipe Yellow Lake. Cool tint. refers to the use of alum (ammonia sort), however, it was chosen to use common alum $\left(\mathrm{KAl}\left(\mathrm{SO}_{4}\right)_{2} \cdot 12 \mathrm{H}_{2} \mathrm{O}\right)$ in all recipes to facilitate a first comparison between them. For this reason, we also decided always to use weld flowers. The introduction of experimental variants such as using ammonium alum $\left(\mathrm{NH}_{4} \mathrm{Al}\left(\mathrm{SO}_{4}\right)_{2} \cdot 12 \mathrm{H}_{2} \mathrm{O}\right)$ will be investigated in the future. All materials were scaled-down from industrial to laboratory scale, and quantities in British measures were converted to SI units [22,23].

$\mathrm{pH}$ measurements were acquired throughout the syntheses. After 1 day left to precipitate, the lakes were centrifuged for $10 \mathrm{~min}$ at $2400 \mathrm{rpm}$, washed with distilled water, and centrifuged again for $5 \mathrm{~min}$ at $3000 \mathrm{rpm}$. The lakes were air-dried and ground in an agate mortar for $15 \mathrm{~min}$ each. 
Table 1. Production name, recipe and pigment code of the synthesis methods for weld lake pigments, adapted from the original text transcribed in Table S1.

\begin{tabular}{|c|c|c|c|}
\hline Production Name & Unique Recipe Code $\S$ & Pigment Code & Synthesis Methods \\
\hline & $\begin{array}{c}\text { 4PP148AL01 } \\
\text { (copy in P4P088L01) }\end{array}$ & WL1 & $\begin{array}{l}\text { A. To } 10 \mathrm{~mL} \text { of boiling water add } 0.2 \mathrm{~g} \text { of } \mathrm{CaCO}_{3} \text { and then } \\
\text { slowly add } 0.86 \mathrm{~g} \text { of } \mathrm{KAl}\left(\mathrm{SO}_{4}\right)_{2} \cdot 12 \mathrm{H}_{2} \mathrm{O} \text {, always stirring. } \\
\text { Leave it to rest and decant the solution; keep the precipitate. } \\
\mathrm{B} \text {. To } 50 \mathrm{~mL} \text { of boiling water add } 2 \mathrm{~g} \text { of weld flowers. Then } \\
\text { add } 0.014 \mathrm{~g} \text { of } \mathrm{KHCO}_{3} \text { and leave it to boil during } 20 \mathrm{~min} \text {. } \\
\text { Filter it and keep the solution. } \\
\text { Put the solution } \mathrm{B} \text { to boil. When boiling, add the precipitate } \\
\text { A and leave it boiling for } 1 \mathrm{~h} \text {, always stirring. Leave it to } \\
\text { rest for } 1 \text { day and filter the yellow lake pigment. }\end{array}$ \\
\hline
\end{tabular}

Yellow from Weld

A. To $10 \mathrm{~mL}$ of boiling water add $0.86 \mathrm{~g}$ of

$\mathrm{KAl}\left(\mathrm{SO}_{4}\right)_{2} \cdot 12 \mathrm{H}_{2} \mathrm{O}$ and then slowly add $0.2 \mathrm{~g}$ of $\mathrm{CaCO}_{3}$, always stirring. Leave it to rest and decant the solution; keep the precipitate.

4PP148AL14

(copy in P4P089L14)
WL2
B. To $50 \mathrm{~mL}$ of boiling water add $2 \mathrm{~g}$ of weld flowers. Then add $0.014 \mathrm{~g}$ of $\mathrm{KHCO}_{3}$ and leave it to boil during $20 \mathrm{~min}$. Filter it and keep the solution.

Put the solution B to boil. When boiling, add the precipitate A and leave it boiling for $1 \mathrm{~h}$, always stirring. Leave it to rest for 1 day and filter the yellow lake pigment.

To $50 \mathrm{~mL}$ of boiling water add $0.43 \mathrm{~g}$ of $\mathrm{K}_{2} \mathrm{CO}_{3}$. When dissolved add $2 \mathrm{~g}$ of weld flowers and leave it to boil during

Yellow Lake.

Cool tint.

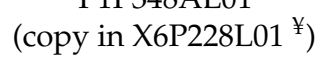

P4P100L10

WL4

Weld Yellow
WL3 $20 \mathrm{~min}$. Filter it and keep the solution. To the yellow solution add $0.86 \mathrm{~g}$ of $\mathrm{KAl}\left(\mathrm{SO}_{4}\right)_{2} \cdot 12 \mathrm{H}_{2} \mathrm{O}$, always stirring. Leave it to rest and filter the yellow lake pigment.

To $50 \mathrm{~mL}$ of boiling water add $0.018 \mathrm{~g}$ of $\mathrm{K}_{2} \mathrm{CO}_{3}$ and then $4 \mathrm{~g}$ of weld flowers. Boil $10 \mathrm{~min}$. Filter it and keep the solution. To the yellow solution add $0.107 \mathrm{~g}$ of $\mathrm{KAl}\left(\mathrm{SO}_{4}\right)_{2} \cdot 12 \mathrm{H}_{2} \mathrm{O}$ and then $0.07 \mathrm{~g}$ of $\mathrm{Na}_{2} \mathrm{~B}_{4} \mathrm{O}_{7} \cdot 10 \mathrm{H}_{2} \mathrm{O}$, always stirring. Leave it to rest and filter the yellow lake pigment.

To $50 \mathrm{~mL}$ of boiling water add $0.018 \mathrm{~g}$ of $\mathrm{K}_{2} \mathrm{CO}_{3}$ and then $2 \mathrm{~g}$ of weld flowers. Boil $10 \mathrm{~min}$. Filter it and keep the solution. To the yellow solution, add $0.177 \mathrm{~g}$ of $\mathrm{Al}(\mathrm{OH})_{3}$, always stirring. Leave it to rest and filter the yellow lake pigment.

\footnotetext{
$\S$ The unique recipe code is the code from the W\&N Database that identifies a database record. ${ }^{¥}$ Although this record is a copy, its title is "Experiment with Weld for Yellow Lake for Water Colours" and is dated 6 October 1854.
}

\subsection{Paint References}

Paint references were prepared using gum arabic as a $20 \%$ solution; the pieces were ground and then added to pure water. The lake pigments were first ground in a glass mortar with pure water and then ground with the binder. The paints were applied on filter paper with a paintbrush and allowed to dry. Filter paper was selected because no additives are present such as brighteners; this was confirmed by checking the filter paper under an UV-lamp (280 nm). The paint references were analyzed by colorimetry.

\subsection{Equipment and Characterization Methods \\ 2.4.1. Colorimetry}

For measuring color, a portable spectrophotometer colorimetry Data Color International was used. Its measuring head's optical system uses diffuse illumination from a pulsed Xenon arc lamp over the $8 \mathrm{~mm}$-diameter measuring area, with $0^{\circ}$ viewing angle geometry. Color coordinates were calculated defining the D65 illuminant and the $10^{\circ} \mathrm{ob}-$ server. The calibration was performed with a white bright standard plate and a total black standard. Color, as perceived by the human eye, may be represented in a three-dimensional system. The color data are presented in the CIE-Lab system. In the Lab cartesian system, 
$\mathrm{L}^{*}$, relative brightness, is represented by the z-axis. Variations in relative brightness range from white $\left(L^{*}=100\right)$ to black $\left(L^{*}=0\right)$. The $\left(a^{*}, b^{*}\right)$ pair represents the hue of the object. The red/green y-axis plots $\mathrm{a}^{*}$ ranging from negative values (green) to positive (red). The yellow /blue $\mathrm{x}$-axis reports $\mathrm{b}^{*}$ going from negative (blue) to positive numbers (yellow).

\subsubsection{High-Performance Liquid Chromatography with a Diode Array Detector} (HPLC-DAD)

For HPLC-DAD analysis, Reseda luteola plant was extracted by placing $1 \mathrm{~g}$ of the dry plant material (as collected from nature) with $100 \mathrm{~mL}$ of methanol:water (70:30, v:v) and heating in a water bath at $60{ }^{\circ} \mathrm{C}$ for one hour, as described in [26]. The dye from lake pigments was extracted by placing in an eppendorf, $10 \mathrm{mg}$ of powder with a $1 \mathrm{~mL}$ solution of oxalic acid (0.2 M):methanol:acetone:water (0.1:3:3:4, v:v), as described in [27].

Prior to HPLC-DAD analysis, all extracts were centrifuged at $12,000 \mathrm{rpm}$ for about $10 \mathrm{~min}$. The supernatant liquid was gently removed and filtered through a $0.45 \mu \mathrm{m}$ filter. Before analysis, the solution was diluted with methanol:water $(70: 30, v: v)$ if necessary.

The analysis was carried out in a Thermofinnigan Surveyor ${ }^{\circledR}$ HPLC-DAD system with a Thermofinnigan Surveyor PDA (Thermofinnigan, San Jose, CA, USA), an autosampler, and a gradient pump. The sample separations were performed in a reversedphase column, RP-18 Nucleosil column (Macherey-Nagel) with $5 \mu \mathrm{m}$ particle size column $(250 \mathrm{~mm} \times 4.6 \mathrm{~mm})$, with a flow rate of $1.7 \mathrm{~mL} / \mathrm{min}$ with the column at a constant temperature of $35^{\circ} \mathrm{C}$. The samples were injected via a Rheodyne injector with a $25 \mu \mathrm{L}$ loop. The elution gradient consisted of two solvents, A: methanol and B: $0.1 \%(v / v)$ perchloric acid aqueous solution. A gradient elution program was used of $0-2 \mathrm{~min}$ isocratic $7 \% \mathrm{~A}, 2-8 \mathrm{~min}$ linear gradient to $15 \% \mathrm{~A}, 8-25 \mathrm{~min}$ linear gradient to $75 \% \mathrm{~A}, 25-27$ min linear gradient to $80 \% \mathrm{~A}, 27-29 \mathrm{~min}$ linear gradient to $100 \% \mathrm{~A}$, and $29-30 \mathrm{~min}$ isocratic $100 \% \mathrm{~A}(10 \mathrm{~min}$ re-equilibration time). The eluted peaks were monitored at $350 \mathrm{~nm}$.

The peaks were integrated and the area of each peak was recorded as well as the percentage. Peak area calculation was done by defining the time intervals for each peak. The area below the peak was integrated within this interval is measured and the percentage of each area is calculated by dividing by the sum of all the peak areas. For this analysis, it was considered the area of the nine peaks visible at $\lambda=350 \mathrm{~nm}$, between 14 and $24 \mathrm{~min}$, as shown in Figure 2.

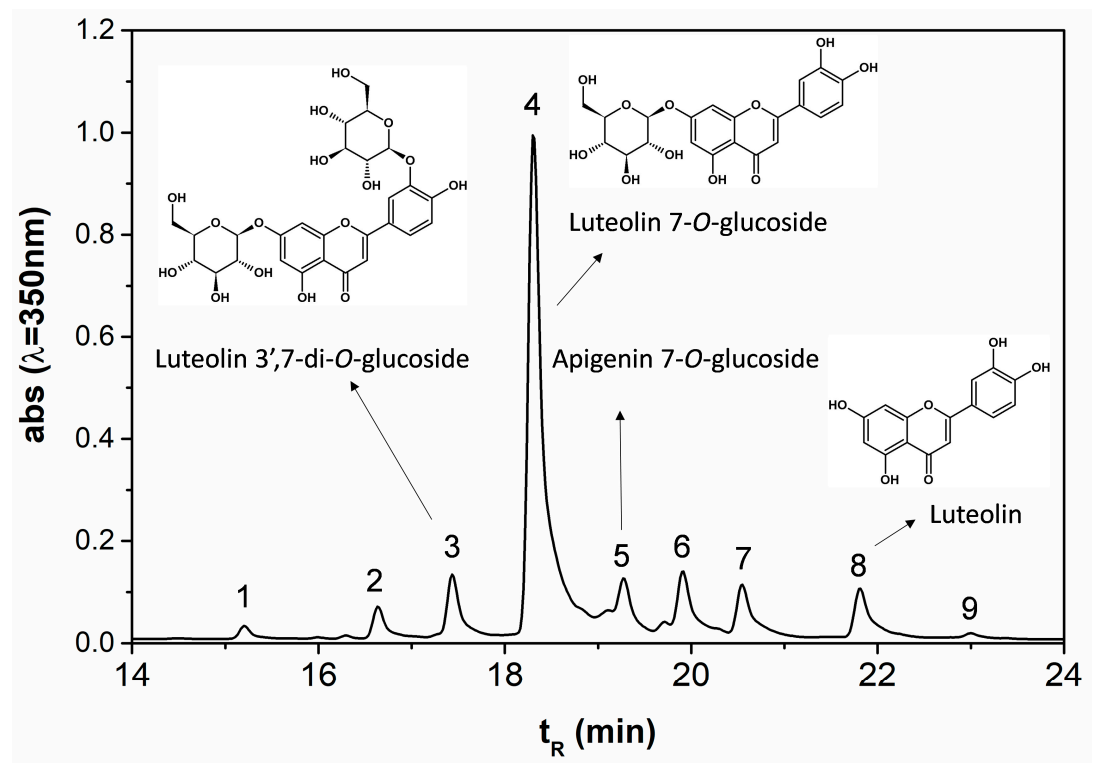

Figure 2. Chromatogram of an extract in $\mathrm{MeOH}: \mathrm{H}_{2} \mathrm{O}(70: 30, v: v)$ of Reseda luteola, $\lambda=350 \mathrm{~nm}$ : (1) apigenin-6,8-di-C-glucoside, (2) luteolin di-O-glucoside; (3) luteolin 3',7-O-glucoside; (4) luteolin 7-O-glucoside, (5) apigenin 7-O-glucoside, (6) chrysoeriol glycoside, (7) luteolin 4' $-\mathrm{O}$-glucoside, (8) luteolin, (9) apigenin. 


\subsubsection{Ultra-High Performance Liquid Chromatography-High Resolution Mass} Spectrometry (UHPLC-DAD-HRMS)

Aliquots of $3 \mu \mathrm{L}$ of plant material were analyzed on a UHPLC Elute system coupled on-line with a quadrupole time-of-flight Impact II mass spectrometer equipped with an ESI source (Bruker Daltoniks, Bremen, Germany). Chromatographic separation was carried out on an RF-C18 Halo column $(150 \mathrm{~mm} \times 2.1 \mathrm{~mm}, 2.7 \mu \mathrm{m}$ particle size, Advanced Material Technology). The mobile phase consisted of water (A) and acetonitrile (B), containing $0.1 \%$ formic acid, at a flow rate of $600 \mu \mathrm{L} / \mathrm{min}$. The elution conditions were as follows: $0-18 \mathrm{~min}$, linear gradient to $50 \% \mathrm{~B} ; 18-20 \mathrm{~min}$, linear gradient to $90 \% \mathrm{~B} ; 20-23 \mathrm{~min}$, isocratic $90 \% \mathrm{~B}$; and 23-24 min, linear gradient to $0 \% \mathrm{~B}$ (followed by $11 \mathrm{~min}$ re-equilibration time). The column and the autosampler were maintained at $45^{\circ} \mathrm{C}$ and $8{ }^{\circ} \mathrm{C}$, respectively. High-resolution mass spectra were acquired in the ESI negative mode. Internal calibration was achieved with an ammonium formate $10 \mathrm{mM}$ solution introduced to the ion source via a $20 \mu \mathrm{L}$ loop at the beginning of each analysis, using a six-port valve. The mass spectrometric parameters were set as follows: end-plate offset: $500 \mathrm{~V}$; capillary voltage: $-2.5 \mathrm{kV}$; nebulizer: 4 bars; dry gas: $8 \mathrm{~L} / \mathrm{min}$; heater temperature: $200{ }^{\circ} \mathrm{C}$; $\mathrm{m} / \mathrm{z}$ range $100-1000 \mathrm{Da}$; acquisition mode: data-dependent analysis (Auto MS/MS), acquisition rate of $3 \mathrm{~Hz}$, and using a dynamic method with a fixed cycle time of 3 , and an isolation window of $0.03 \mathrm{Da}$. Data acquisition and processing were performed using Data Analysis 4.2 software.

\subsubsection{Fourier Transform Infrared Spectroscopy (FTIR)}

Infrared analyses were carried out with a Nicolet Nexus spectrophotometer. The pigments were prepared as $\mathrm{KBr}$ pellets, and spectra were collected in transmission mode between $4000 \mathrm{~cm}^{-1}$ and $650 \mathrm{~cm}^{-1}$, with a resolution of $8 \mathrm{~cm}^{-1}$ and 64 scans. The spectra are shown here as acquired, without corrections or any further manipulations.

\section{Results and Discussion}

\subsection{Weld Lake Pigment Recipes in the Winsor E Newton 19th Century Archive Database}

From a total of 1511 database records for yellow pigments, $42 \%$ pertains to yellow lakes. Although the majority of these records pertain to quercitron-based products, 12 of these mention weld, as referred above. Interestingly, the five recipes to prepared weld lake pigments were discovered in manuscript books belonging to the founder Henry Charles Newton and his son Arthur Henry Newton. The recipes were found under the names: "Yellow from weld", "Yellow Lake. Cool tint." and "Weld Yellow", as described in Tables 1 and 2. It is important to note that the pigments prepared from the first three recipes (WL1, WL2 and WL3) were originally produced with $12.7 \mathrm{kgs}$ of weld plants, whereas those from the last recipes ((WL4 and WL5) were produced with $0.9 \mathrm{~kg}$, which suggests the latter were experiments. Nonetheless, all recipes were reproduced, and the $\mathrm{pHs}$ of the extraction solution and after precipitation of the weld lake pigments obtained are also presented in Table 2.

As Table 1 shows, W\&N was extracting weld in a neutral media for most recipes, excluding WL3 recipe, which involved a basic media. This was accomplished by the addition of carbonate compounds $\left(\left(\mathrm{KHCO}_{3}\right.\right.$ and $\left.\mathrm{K}_{2} \mathrm{CO}_{3}\right)$ that "assist the extraction of the colouring matter" as stated in the recipe Yellow from Weld (WL1 and WL2). The latter recipe also includes the preparation of what $W \& N$ called the "body" of the pigment formulation, which involves mixing calcium carbonate $\left(\mathrm{CaCO}_{3}\right)$ and alum $\left(\mathrm{KAl}\left(\mathrm{SO}_{4}\right)_{2} \cdot 12 \mathrm{H}_{2} \mathrm{O}\right.$. WL1 and WL2 differ in the order of addition of these ingredients. According to W\&N, the pigment resulting from WL1 was "rather pale because the body was not thoroughly homogeneous" and the improved process WL2 resulted in a color "deeper \& looked brighter". Experimentally, we observe a yellow with a stronger red component, see Table 3. Curiously, they also refer "the quantity of yellow was less" for the WL2, however, we did not obtain this result as the yields are very similar, as presented in Table 2. In fact, those that experimentally presented the best yield of all five recipes were WL1 and WL2, while WL4 had the worst yield. Regarding recipe WL3, the yield experimentally obtained was very similar to W\&N. 
According to them, this recipe produced "a lively kind of yellow lake for sale \&c. Greenish in hue, bright in the drop \& full coloured" and when "tried in oil it produces a very beautiful yellow lake_very cool_bright \& strong". Although the resulting pigment presents one of the lowest red component values $\left(a^{*} \approx 2\right)$, it did not show a greenish hue. This may be related to incomplete precipitation of all coloring matter as in the original recipe (see Table S1) is claimed that the quantity of alum used by W\&N "was found to precipitate the colour entirely, leaving only a very faint tinge of yellow in the supernatant". This was not observed in our experiment and will also be addressed in future work.

Table 2. Production name, ingredients, synthesis methods, final $\mathrm{pHs}$ and yields for W\&N's weld lake pigments.

\begin{tabular}{|c|c|c|c|c|c|c|}
\hline Dye Source & \multicolumn{2}{|c|}{ Extraction Method } & \multicolumn{3}{|c|}{ Complexing Agent } & \multirow{2}{*}{$\begin{array}{c}\text { Additives } \\
\text { Sodium Borate } \\
\mathrm{Na}_{2} \mathrm{~B}_{4} \mathrm{O}_{7}\end{array}$} \\
\hline Weld & $\begin{array}{c}\text { Potassium } \\
\text { bicarbonate } \\
\mathrm{KHCO}_{3}\end{array}$ & $\begin{array}{c}\text { Potassium } \\
\text { carbonate } \\
\mathrm{K}_{2} \mathrm{CO}_{3}\end{array}$ & $\begin{array}{c}\text { Alum } \\
\mathrm{KAl}\left(\mathrm{SO}_{4}\right)_{2}\end{array}$ & $\begin{array}{c}\text { Hydrated } \\
\text { alumina } \\
\mathrm{Al}(\mathrm{OH})_{3}\end{array}$ & $\begin{array}{c}\text { Calcium } \\
\text { carbonate } \\
\mathrm{CaCO}_{3}\end{array}$ & \\
\hline $\begin{array}{l}\text { Production } \\
\text { name }\end{array}$ & Code & \multicolumn{2}{|c|}{ Synthesis } & $\begin{array}{c}\mathrm{pH} \\
\text { extraction } 1\end{array}$ & $\begin{array}{l}\mathrm{pH} \\
\text { final }\end{array}$ & $\eta(\%)^{2}$ \\
\hline \multirow{2}{*}{$\begin{array}{l}\text { Yellow from } \\
\text { Weld }\end{array}$} & WL1 & Ext & & 6.18 & 4.05 & $\begin{array}{c}\eta_{W \& N}=25 \% \\
\eta_{E X P}=31 \%\end{array}$ \\
\hline & WL2 & Ext & $\stackrel{\text { tion }}{\longrightarrow}$ & 6.27 & 3.36 & $\begin{array}{c}\eta_{W \& N}=18 \% \\
\eta_{E X P}=32 \%\end{array}$ \\
\hline $\begin{array}{l}\text { Yellow Lake. } \\
\text { Cool tint. }\end{array}$ & WL3 & Ext & ation & 9.46 & 3.63 & $\begin{aligned} \eta_{\mathrm{W} \& \mathrm{~N}} & =12.5 \% \\
\eta_{\mathrm{EXP}} & =12 \%\end{aligned}$ \\
\hline \multirow{2}{*}{ Weld Yellow } & WL4 & Ext & ition & 6.02 & 5.07 & $\begin{array}{c}\eta_{\mathrm{W \& N}}=\text { n.a. } \\
\eta_{\mathrm{EXP}}=6 \%\end{array}$ \\
\hline & WL5 & Ext & ition & 6.35 & 6.15 & $\begin{array}{c}\eta_{W \& N}=\text { n.a. } \\
\eta_{E X P}=9 \%\end{array}$ \\
\hline
\end{tabular}

${ }^{1}$ The $\mathrm{pH}$ extraction is related to the $\mathrm{pH}$ after extracting the plant material and subsequent filtration. ${ }^{2}$ The observed yield ( $\eta$ ) was calculated as follows: (final lake amount $) \div($ weld amount $) \times 100$. $\eta_{W \& N}-$ observed yield calculated by the quantities given by W\&N, see Table S1; $\eta_{\mathrm{EXP}}-$ observed yield calculated by the quantities obtained experimentally.

Table 3. Colorimetry, HPLC chromatograms and infrared spectra of the weld lake pigments synthesized applied over filter paper, with gum arabic media. HPLC chromatograms were obtained from the extracts of the lake pigments. For more details, please see text.

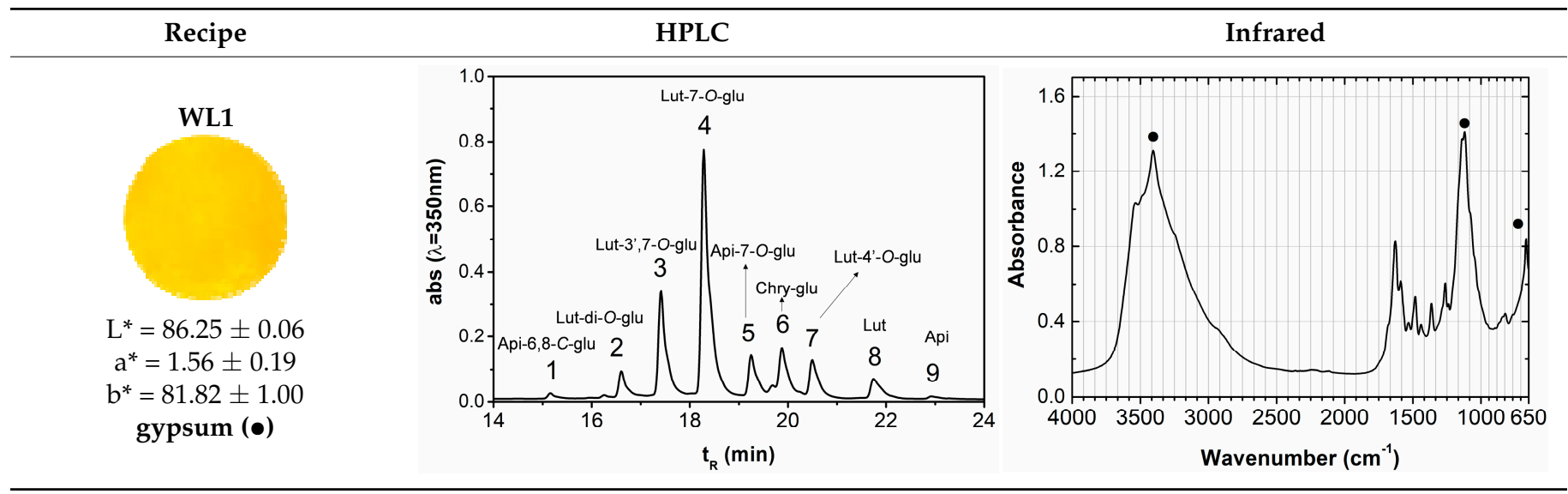


Table 3. Cont.

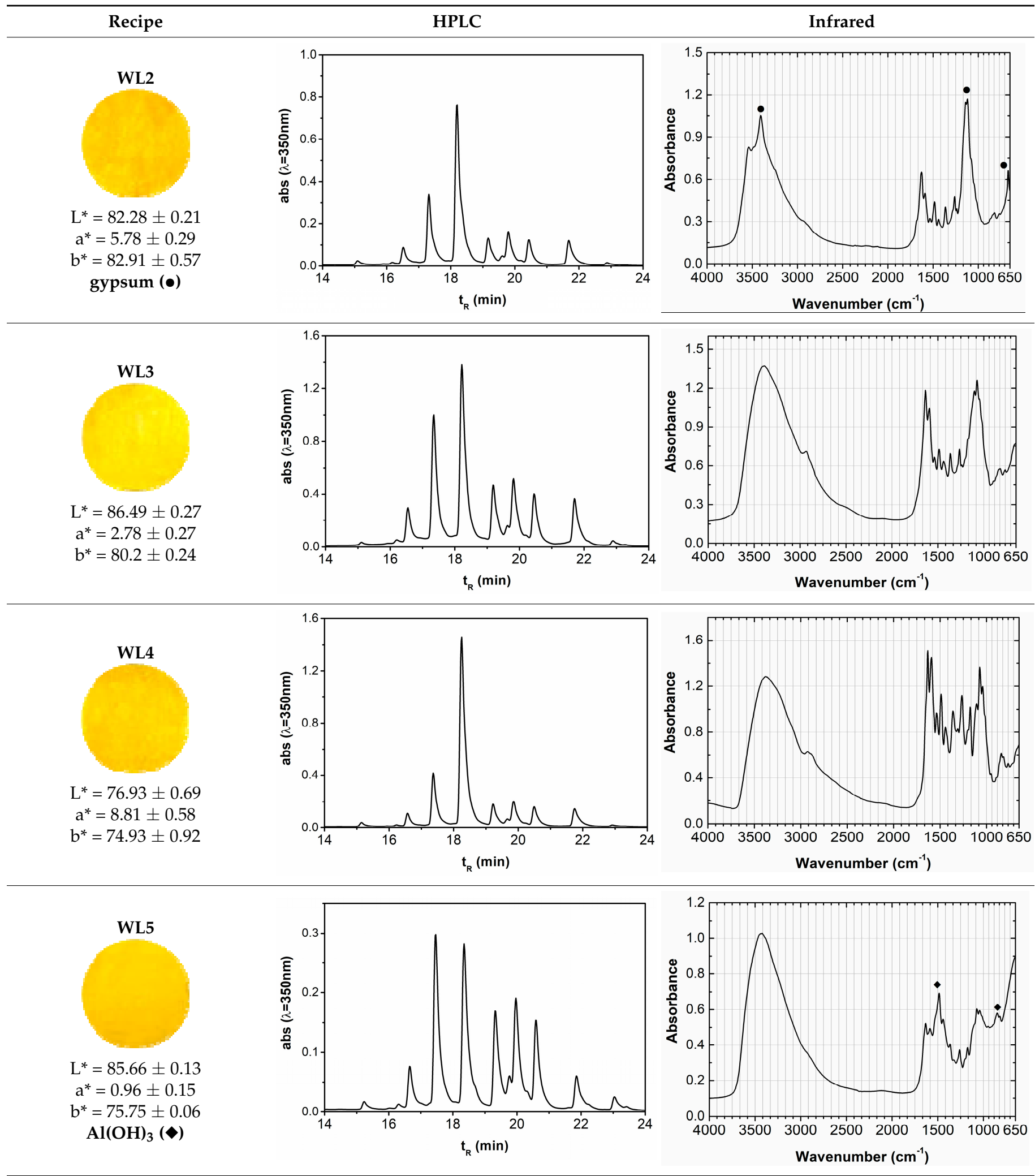

The complexing agent always used was $\mathrm{Al}^{3+}$ in the form of alum $\left(\mathrm{KAl}\left(\mathrm{SO}_{4}\right)_{2} \cdot 12 \mathrm{H}_{2} \mathrm{O}\right)$ in the majority of the recipes and hydrated alumina $\left(\mathrm{Al}(\mathrm{OH})_{3}\right)$ in WL5 recipe; however, 
complexation with $\mathrm{Ca}^{2+}$ cannot be excluded as this has been observed for W\&N 19th century cochineal lake pigments [18]. The addition of borax $\left(\mathrm{Na}_{2} \mathrm{~B}_{4} \mathrm{O}_{7}\right)$ was also experimented with alum in WL4 recipe. The $\mathrm{pH}$ after precipitation was slightly acidic, between 3 and 6 , but always resulted in bright yellow lake pigments, as shown in Table 3. The reasoning for the production methods found is discussed below.

\subsection{Extraction Method}

The analysis of the plant extract was done by HPLC-DAD-HRMS. It was possible to find as a major chromophore Lut-7-O-glu, and minor compounds, Api-6,8-C-glu, Lut-di-Oglu, Lut-3',7-O-glu; Api-7-O-glu, Chry-gly, Lut-4'-O-glu, Lut and Api, see Figure 2. This is in accordance with what has been reported in the literature $[6,8,9]$. It was confirmed that the chromophores identified by HPLC-HRMS were the same as observed by HPLC-DAD.

For both WL1 and WL2 recipes, potassium bicarbonate is added to the plant material' solution, raising the $\mathrm{pH}$ to a neutral media $(\mathrm{pH} \sim 6)$. For the rest of the recipes, potassium carbonate was added previously to the weld, also resulting in a neutral media ( $\mathrm{pH} \sim 6)$, except for the WL3 recipe that remained at a basic media. Although the recipes present two different extraction methods, they do not influence the chromophores extracted as the chromatographic profiles are similar, see Figure 2 and Figure S1.

It is very interesting the use of carbonates $\left(\mathrm{KHCO}_{3}\right.$ and $\left.\mathrm{K}_{2} \mathrm{CO}_{3}\right)$ for the extraction of the flavonoids. The use of such extract solutions instead of water was possibly to allow the highest amount of lake pigment. Favaro et al. used fluorimetric titration to characterize the various luteolin species detected within the $\mathrm{pH}$ range explored $(\mathrm{pH}=2-12)$ [28]: neutral form $(\mathrm{pH}<5)$, mono-anion ( $\mathrm{pH} \sim 7)$, di-anion $(\mathrm{pH} \sim 9)$ and tri-anion $(\mathrm{pH} \sim 12)$, and the successive deprotonations occur in the order 7-OH; 4'-OH; $3^{\prime}-\mathrm{OH}$ or/and 5-OH [28]. In WL3, WL4 and WL5 the extraction is carried out in a basic $\mathrm{pH}$, turning neutral after the addition of the plant material. This creates the optimum conditions for the metal chelation through the $\mathrm{OH}$ at $\mathrm{C}^{5}$ and the carbonyl at $\mathrm{C}^{4}$, since the first is deprotonated only at $\mathrm{pH} \approx 10.3$, as mentioned above.

\subsection{Characterization of the Weld Lake Pigments}

A summary of the multi-analytical results of Colorimetry, High-Performance Liquid Chromatography-Diode Array Detector (HPLC-DAD) and Fourier Transform Infrared Spectroscopy (FTIR) for the weld lake pigments prepared may be observed in Table 3.

\subsubsection{HPLC-DAD Analysis}

Other authors have done an extensive analysis of the characterization of weld by HPLC, including quantitation of the chromophores $[6,8-10,29,30]$. Based on this, in this work, we only compared the chromatographic profiles of the lake pigments using HPLCDAD, which is preferable to perform a semi-quantification.

When analyzing the HPLC chromatograms of the weld lake pigment extracts, some differences are visible, as shown in Table 3. The two variants of recipe Yellow from Weld (WL1 and WL2) present the same chromatographic profile, indicating that the order in which alum and calcium carbonate are added does not affect the chromatographic profile, i.e., the percentage of chromophores present, as seen in Table S2. However, when compared with the extract, in Figure 2, it is possible to see that both lake pigments present a higher percentage of Lut-3',7-O-glu than the plant extract (15.35-17.25\% in the lake pigment when compared with $4.92 \%$ of the extract). Considering that the extracts in $\mathrm{K}_{2} \mathrm{CO}_{3}$ and $\mathrm{KHCO}_{3}$ presented the same chromatographic profile as in $\mathrm{MeOH}: \mathrm{H}_{2} \mathrm{O}$ (see Figure S1), the difference is not due to different extraction methods, but possibly to a higher preference of complexation for the di-glucoside. Interestingly, this difference is even higher in the lake pigment from WL3 and WL5, where the Lut-3',7-O-gluc represents $20.91 \%$ and $23,05 \%$ of the total peak area, while the Lut-7-O-glu represents $30.26 \%$ and $18.63 \%$, respectively. WL3 is the only recipe with the addition of alum to an extraction solution of Reseda luteola at a basic $\mathrm{pH}$ of around 9. Moreover, WL5 also has a higher percentage of Api-7-O-glu, representing 
$11.22 \%$ of the total peak area. WL5 is the only recipe where alumina is added. Regarding the recipe $W L 4$, it has the closest chromatographic profile to that of the extraction, with $13.17 \%$ of luteolin $3^{\prime}, 7$-di-O-glucoside and $52.551 \%$ of luteolin 7 -O-glucoside.

\subsubsection{FTIR Analysis}

Both yellow lake pigments from the recipe Yellow from Weld (WL1 and WL2) have shown similar FTIR results as observed by HPLC-DAD. Notably, the formation of gypsum $\left(\mathrm{CaSO}_{4} \cdot 2 \mathrm{H}_{2} \mathrm{O}\right)$ by FTIR was detected, due to its characteristic absorption bands for $v \mathrm{OH}$ at $3405 \mathrm{~cm}^{-1}, v_{\text {as }}\left(\mathrm{SO}_{4}{ }^{2-}\right)$ at $1132 \mathrm{~cm}^{-1}$ and $\delta_{\mathrm{as}}\left(\mathrm{SO}_{4}{ }^{2-}\right)$ at $670 \mathrm{~cm}^{-1}$ [31], as observed in Table 3 . Gypsum was not directly added but was rather a product of the reaction between alum $\left(\mathrm{KAl}\left(\mathrm{SO}_{4}\right)_{2}\right)$ and calcium carbonate $\left(\mathrm{CaCO}_{3}\right)$. The reason why $\mathrm{W} \& \mathrm{~N}$ chose to create gypsum through a reaction rather than adding it directly is still unclear at the moment. Further experimentation will be performed using gypsum directly in the recipe to understand the role of this reaction.

As may be seen in Table 3, FTIR analysis of all yellow lake pigments shows bands attributed to flavonoids-metal complexes, which is very clear in the infrared spectra of WL3 and WL4, where only alum was added, plus borax in the latter recipe; the role of this ingredient is also still to be investigated. A more thorough analysis of the infrared data of the flavonoids-metal complexes is offered below. Besides identifying gypsum in WL1 and WL2 pigments, it was also detected the presence of hydrated alumina in the WL5 lake pigment, due to its characteristic absorption bands for $\delta\left(\mathrm{H}_{2} \mathrm{O}\right)$ at $1485 \mathrm{~cm}^{-1}$ and the $\delta(\mathrm{Al}-\mathrm{OH})$ at $852 \mathrm{~cm}^{-1}[31]$, as shown in Table 3.

\subsection{Infrared Markers of Weld Lake Pigments}

Although infrared spectroscopy has rarely been used to characterize flavonoids, several studies have proven its effectiveness in studying flavonoids-metal complexes [12,13]. Machado et al. [32] did DFT calculations of IR and Raman spectroscopies of hydroxyflavones, and their assignments are summarized in Table 4.

As mentioned above, flavonoids-metal complexes are observed in the infrared spectra of WL3 and WL4. Figure 3 compares the two lake pigments and references of luteolin and luteolin 7-O-glucoside and shows the similarity between the infrared spectra, namely between WL4 and luteolin 7-O-glucoside. These data are corroborated by the HPLCDAD analysis, since this recipe has $53.31 \%$ of luteolin $7-O$-glucoside, when compared with the $30.38 \%$ of the recipe WL3. The presence of a glucoside in position $7-\mathrm{OH}$ shifted the vibrational frequency from 1186 to $1179 \mathrm{~cm}^{-1}$. The fact that both lakes show lower frequencies, at 1178 and $1173 \mathrm{~cm}^{-1}$, corroborates with the HPLC data. The reference of luteolin $3^{\prime}, 7$-di-O-glucoside will provide more insight into the effect of glucosides in the infrared spectra, and further studies are underway.

Regarding the presence of an organometallic complex, the stretching vibration of $\mathrm{C}=\mathrm{O}$ of luteolin at $1666 \mathrm{~cm}^{-1}$ is shifted to $1632 \mathrm{~cm}^{-1}$. According to Dong, this shift is characteristic of the existence of a complex [12]. It is the co-ordination of carbonyl oxygen with metal ion bonded to $5-\mathrm{OH}$ group of $\mathrm{A}$ ring and 4-CO carbonyl group of $\mathrm{C}$ ring $[12,33,34]$. This is also visible in the stretching at $1613 \mathrm{~cm}^{-1}$. Moreover, the $\mathrm{OH}$ bending of $C^{5}$ shifts from $1509 \mathrm{~cm}^{-1}$ to $1484-9 \mathrm{~cm}^{-1}$, probably also due to the metal coordination. Another possible indication of metal complexation in positions $\mathrm{OH}\left(\mathrm{C}^{5}\right)$ and $\mathrm{CO}\left(\mathrm{C}^{4}\right)$ is the decrease from $1096 \mathrm{~cm}^{-1}$ to $1077-68 \mathrm{~cm}^{-1}$ from the stretching of $C^{3}-C^{4}$. In fact, the extraction solution of WL3 had $\mathrm{pH} \sim 9.4$, the optimum conditions for the metal chelation in the $\mathrm{OH}$ at $\mathrm{C}^{5}$ and the carbonyl at $\mathrm{C}^{4}$. The analysis of luteolin, both as aglycone and with glucosides, complexed with $\mathrm{Al}^{3+}$ is ongoing. 

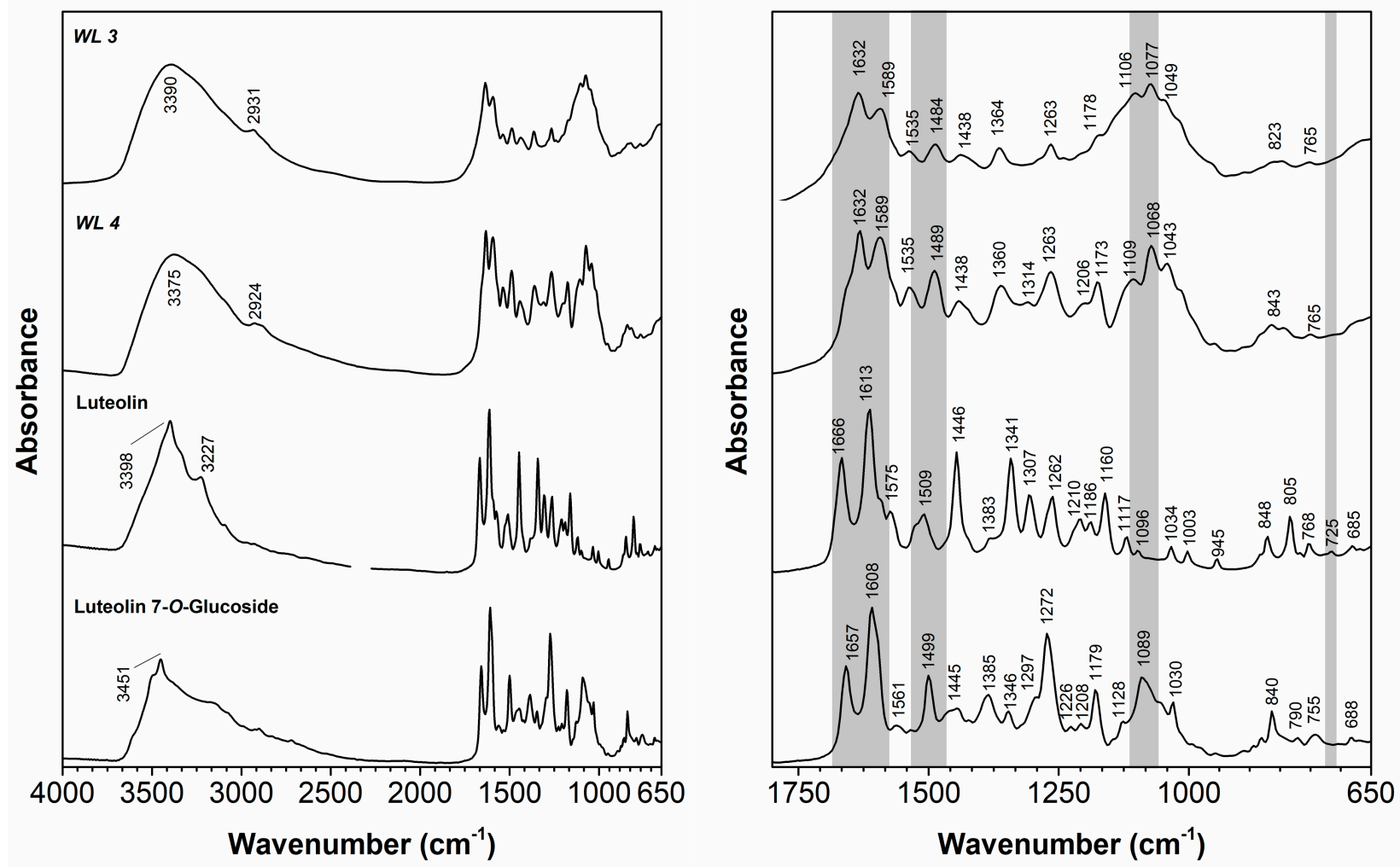

Figure 3. Infrared spectra of weld lake pigments Yellow Lake. Cool tint. (WL3) and Weld yellow (WL4), and references of Lut and Lut-7-O-glu.

Table 4. Infrared assignments for luteolin, luteolin 7-O-glucoside and weld lake pigments WL3 \& WL4. Highlighted in grey are the vibrations correlated with the A ring and positions $\mathrm{C}^{5}-\mathrm{OH}$ and $\mathrm{C}^{4}=\mathrm{O}$, metal chelating groups.

\begin{tabular}{|c|c|c|c|c|c|}
\hline \multirow[b]{2}{*}{ Lut } & \multirow[b]{2}{*}{ Lut-7-O-glu } & \multirow[b]{2}{*}{ WL3 } & \multirow[b]{2}{*}{ WL4 } & \multicolumn{2}{|c|}{ Literature [32] } \\
\hline & & & & Lut & Assignments \\
\hline 3398 & 3451 & 3390 & 3375 & $\sim 3400$ & $\begin{array}{l}v\left(\mathrm{O}^{3 \prime}-\mathrm{H}\right) \\
v\left(\mathrm{O}^{7}-\mathrm{H}\right) \\
v\left(\mathrm{O}^{\left.4^{\prime}-\mathrm{H}\right)}\right.\end{array}$ \\
\hline 3227 & - & - & - & & $v\left(\mathrm{O}^{5}-\mathrm{H}\right)$ \\
\hline- & - & 2931 & 2924 & & \\
\hline 1666 & 1657 & 1632 & 1632 & 1656 & $\begin{array}{l}v(\mathrm{C}=\mathrm{O}) \\
v\left(\mathrm{C}^{2}-\mathrm{C}^{3}\right) \\
\delta\left(\mathrm{O}^{3}-\mathrm{H}\right)\end{array}$ \\
\hline 1613 & 1608 & 1589 & 1589 & 1612 & $\begin{array}{l}v(\mathrm{C}=\mathrm{O}), \delta(\mathrm{O}-\mathrm{H}), \\
\delta\left(\mathrm{O}^{4^{\prime}}-\mathrm{H}\right)\end{array}$ \\
\hline 1575 & - & - & - & 1575 & $\begin{array}{l}v(\mathrm{C}=\mathrm{O}), \delta(\mathrm{O}-\mathrm{H}), \\
\delta(\mathrm{O}-\mathrm{H})\end{array}$ \\
\hline - & 1561 & - & - & 1561 & $\begin{array}{l}v\left(\mathrm{C}^{2}=\mathrm{C}^{3}\right) \\
\delta\left(\mathrm{O}^{5}-\mathrm{H}\right) \\
\delta\left(\mathrm{O}^{\left.4^{\prime}-\mathrm{H}\right)}\right. \\
\delta\left(\mathrm{O}^{7}-\mathrm{H}\right)\end{array}$ \\
\hline- & - & 1535 & 1535 & 1518 & $\begin{array}{l}\delta\left(\mathrm{O}^{7}-\mathrm{H}\right) \\
\delta(\mathrm{O}-\mathrm{H})^{\mathrm{A}}\end{array}$ \\
\hline 1509 & 1499 & 1484 & 1489 & 1507 & $\delta\left(\mathrm{O}^{5}-\mathrm{H}\right)$ \\
\hline
\end{tabular}


Table 4. Cont.

\begin{tabular}{|c|c|c|c|c|c|}
\hline \multirow{2}{*}{ Lut } & \multirow{2}{*}{ Lut-7-O-glu } & \multirow{2}{*}{ WL3 } & \multirow{2}{*}{ WL4 } & \multicolumn{2}{|c|}{ Literature [32] } \\
\hline & & & & Lut & Assignments \\
\hline 1446 & 1445 & & & 1456 & $\delta(\mathrm{O}-\mathrm{H})^{\mathrm{B}}$ \\
\hline - & - & 1438 & 1438 & 1439 & $\begin{array}{l}\delta(\mathrm{O}-\mathrm{H})^{\mathrm{B}} \\
\delta\left(\mathrm{O}^{3}-\mathrm{H}\right)\end{array}$ \\
\hline 1383 & 1385 & 1364 & 1360 & 1367 & $\begin{array}{l}v_{\mathrm{s}}\left(\mathrm{C}-\mathrm{O}^{1}-\mathrm{C}^{2}\right) \\
\delta\left(\mathrm{O}^{4^{\prime}}-\mathrm{H}\right)\end{array}$ \\
\hline \multirow[t]{2}{*}{1341} & 1346 & - & - & - & n.a. \\
\hline & & - & 1314 & 1313 & $\begin{array}{l}\delta(\mathrm{O}-\mathrm{H}) \\
v\left(\mathrm{C}^{4^{\prime}}-\mathrm{O}\right)\end{array}$ \\
\hline 1307 & - & - & - & 1303 & $v\left(\mathrm{C}^{4^{\prime}}-\mathrm{O}\right)$ \\
\hline- & 1297 & - & - & 1284 & $v\left(\mathrm{C}^{4^{\prime}}-\mathrm{O}\right)$ \\
\hline 1262 & 1272 & 1263 & 1263 & 1263 & $\begin{array}{l}\delta\left(\mathrm{C}^{2}-\mathrm{H}\right) \\
v\left(\mathrm{C}^{2}-\mathrm{O}^{1}\right) \\
v(\mathrm{C}-\mathrm{C}), \delta\left(\mathrm{O}^{5}-\mathrm{H}\right)\end{array}$ \\
\hline- & 1226 & - & - & - & n.a. \\
\hline 1210 & 1208 & - & 1206 & 1210 & $\begin{array}{l}\delta(\mathrm{O}-\mathrm{H})^{\mathrm{A}}, \\
v\left(\mathrm{C}^{2}-\mathrm{O}^{1}\right)\end{array}$ \\
\hline 1186 & 1179 & 1178 & 1173 & 1194 & $\begin{array}{l}\delta\left(\mathrm{C}^{6}-\mathrm{H}\right) \\
\delta\left(\mathrm{O}^{7}-\mathrm{H}\right)\end{array}$ \\
\hline 1160 & - & - & - & 1162 & $\begin{array}{l}\delta(\mathrm{O}-\mathrm{H})^{\mathrm{B}} \\
\delta\left(\mathrm{O}^{7}-\mathrm{H}\right)\end{array}$ \\
\hline 1117 & 1128 & 1106 & 1109 & 1120 & $\begin{array}{l}\delta\left(\mathrm{C}^{2}-\mathrm{H}\right) \\
\delta(\mathrm{O}-\mathrm{H})^{\mathrm{B}}\end{array}$ \\
\hline 1096 & 1089 & 1077 & 1068 & 1094 & $\begin{array}{l}v_{\mathrm{s}}\left(\mathrm{C}-\mathrm{O}^{1}-\mathrm{C}^{2}\right), \\
v\left(\mathrm{C}-\mathrm{O}^{1}\right), \\
v\left(\mathrm{C}^{3}-\mathrm{C}^{4}\right), \phi_{\mathrm{ip}} \mathrm{A}, \mathrm{B}, \\
\delta(\mathrm{O}-\mathrm{H}), \delta\left(\mathrm{O}^{7}-\mathrm{H}\right)\end{array}$ \\
\hline 1034 & 1030 & 1049 & 1043 & 1031 & $\begin{array}{l}v_{\mathrm{s}}\left(\mathrm{C}-\mathrm{O}^{1}-\mathrm{C}^{2}\right) \\
\phi_{\mathrm{ip}} \mathrm{A}, \mathrm{B}, \delta\left(\mathrm{C}^{2}-\mathrm{H}\right)\end{array}$ \\
\hline 1003 & - & - & - & 999 & $\phi^{\mathrm{A}}+\phi_{\mathrm{ip}}^{\mathrm{B}}$ \\
\hline 945 & - & - & - & 946 & $\begin{array}{l}\phi^{\mathrm{A}, \mathrm{B}}, \\
\Delta\left(\mathrm{C}^{3}-\mathrm{C}^{4}=\mathrm{O}\right), \\
v\left(\mathrm{O}^{1}-\mathrm{C}^{2}\right)\end{array}$ \\
\hline 848 & 840 & 823 & 843 & 839 & $\gamma\left(\mathrm{C}^{2}-\mathrm{H}\right)$ \\
\hline 805 & 790 & - & - & & n.a. \\
\hline 768 & 755 & 765 & 765 & 766 & $\phi^{\mathrm{A}}$ \\
\hline 725 & - & - & - & 728 & $\begin{array}{l}\phi_{\mathrm{op}}{ }^{\mathrm{A}}, \\
\Gamma\left(\mathrm{C}^{3}-\mathrm{C}^{4}=\mathrm{O}\right), \\
\gamma\left(\mathrm{O}^{5}-\mathrm{H}\right)\end{array}$ \\
\hline 685 & 688 & - & - & & n.a. \\
\hline
\end{tabular}

Annotations: $\gamma$-stretching, $\phi$-aromatic ring normal vibrations, $\delta$-in-plane deformation, $\gamma$-out-of-plane deformation, $\Gamma$-out-of-plane deformation of skeleton atoms, $\Delta$-in-plane deformation of skeleton atoms, ip—in-plane, op—out-of-plane, $s$-symmetric mode.

\section{Conclusions}

The W\&N 19th century Archive Database has proven, once more, to be an exceptional source of information on 19th-century artists' materials and their commercial preparation, enabling the first study of five W\&N manufacturing processes for yellow lake pigments from weld. 
This investigation showed that W\&N 19th-century methods for preparing weld lake pigments involved extracting the dye in neutral-basic media by adding carbonate compounds $\left(\mathrm{KHCO}_{3}\right.$ and $\left.\mathrm{K}_{2} \mathrm{CO}_{3}\right)$ and complexation of flavonoid compounds was always achieved by the addition of $\mathrm{Al}^{3+}$. Five bright yellow lake pigments were obtained and characterized by a multi-analytical approach. Their chromatographic profiles display as main yellows, luteolin 7-O-glucoside (Lut-7-O-glu) or both Lut-7-O-glu plus luteolin 3',7-Oglucoside (Lut-3',7-O-glu). In two of the processes, the presence of gypsum $\left(\mathrm{CaSO}_{4} \cdot 2 \mathrm{H}_{2} \mathrm{O}\right)$ was detected by FTIR, being formed as a by-product of the reaction of alum and $\mathrm{CaCO}_{3}$. This work also offers the first identification of weld lake pigments' characteristic infrared bands: the stretching vibration of $\mathrm{C}=\mathrm{O}$ at $1632 \mathrm{~cm}^{-1}$, the $\mathrm{OH}$ of $\mathrm{C}^{5}$ bending at c. $1484-9 \mathrm{~cm}^{-1}$, the stretching of $\mathrm{C}^{3}-\mathrm{C}^{4}$ at $1077-68 \mathrm{~cm}^{-1}$, all clear indications of metal complexation in positions $\mathrm{OH}\left(\mathrm{C}^{5}\right)$ and $\mathrm{CO}\left(\mathrm{C}^{4}\right)$ of flavonoid compounds.

The five recipes result in two types of lake pigments: yellows in which a filler, such as gypsum, is present (WL1 and WL2) and yellows in which the lake pigment was found in an aluminate matrix (WL3 as well as WL4 and WL5). In the first type, the paints' mechanical performance is controlled by the filler [35], and the pigments are more opaque when applied as oil paints. On the other hand, the second type allows the preparation of translucent paints that can be applied as glazes.

The yields obtained experimentally were very similar or better than those of W\&N, excluding recipes $W L 4$ and WL5, which were considered experiments. In the future, we intend to investigate variants of the processes and explore the full precipitation of the coloring matter as described by W\&N in WL3. Moreover, since infrared spectroscopy revealed a powerful technique for the characterization of flavonoids-metal chelation, further work is ongoing with the analysis of other luteolin and apigenin "type-chromophores" complexed with $\mathrm{Al}^{3+}$.

The pigment reconstructions will be fundamental to advancing on degradation studies and supporting analytical methodologies useful for identifying weld lake pigments in artworks, contributing to ensuring effective conservation and authentication procedures.

Supplementary Materials: The following are available online at https:/ / www.mdpi.com/2571-940 $8 / 4 / 1 / 26 /$ s1.

Author Contributions: Conceptualization, P.N. and V.O.; methodology, P.N. and V.O.; synthesis, M.V.; investigation, M.V., P.N., V.O., A.C., M.C.O.; writing-original draft preparation, P.N. and V.O.; writing-review and editing, P.N., V.O., A.C., M.J.M.; funding acquisition, M.J.M. All authors have read and agreed to the published version of the manuscript.

Funding: This work was supported by the Associate Laboratory for Green Chemistry-LAQV, which is financed by national funds from FCT/MCTES (UIDB/50006/2020 and UIDP/50006/2020). FCT/MCTES also funded the project "Polyphenols in Art: chemistry and biology hand in hand with conservation of cultural heritage" (PTDC/QUI-OUT/29925/2017), in which this work was developed.

Institutional Review Board Statement: Not applicable.

Data Availability Statement: Not applicable.

Conflicts of Interest: The authors declare no conflict of interest.

\section{References}

1. Cardon, D. Natural Dyes: Sources, Tradition, Technology and Science; Archetype Publications: London, UK, 2007.

2. Kirby, J.; van Bommel, M.; Verhecken, A. Natural Colorants for Dyeing and Lake Pigments: Practical Recipes and Their Historical Sources; Archetype Publications: London, UK, 2014.

3. Clarke, M. Colours versus colorants in art history: Evaluating lost manuscript yellows. Rev. História Arte 2011, 1, $138-151$.

4. Zhang, X.; Good, I.; Laursen, R. Characterization of dyestuffs in ancient textiles from Xinjiang. J. Archaeol. Sci. 2008, 35, $1095-1103$. [CrossRef]

5. Liu, J.; Guo, D.; Zhou, Y.; Wu, Z.; Li, W.; Zhao, F.; Zheng, X. Identification of ancient textiles from Yingpan, Xinjiang, by multiple analytical techniques. J. Archaeol. Sci. 2011, 38, 1763-1770. [CrossRef] 
6. Marques, R.; Sousa, M.M.; Oliveira, M.C.; Melo, M.J. Characterization of Weld (Reseda luteola L.) and spurge flax (Daphne gnidium L.) by high-performance liquid chromatography-diode array detection-mass spectrometry in Arraiolos historical textiles. J. Chromatog. A 2009, 1216, 1395-1402. [CrossRef]

7. Nyström, I. Spectroscopic analysis of artists' pigments and materials used in southern Swedish painted wall hangings from the eighteenth and nineteenth centuries. Stud. Conservat. 2015, 60, 353-367. [CrossRef]

8. Moiteiro, C.; Gaspar, H.; Rodrigues, A.I.; Lopes, J.F.; Carnide, V. HPLC quantification of dye flavonoids in Reseda luteola L. from Portugal. J. Sep. Sci. 2008, 31, 3683-3687. [CrossRef] [PubMed]

9. Cristea, D.; Bareau, I.; Vilarem, G. Identification and quantitative HPLC analysis of the main flavonoids present in Weld (Reseda luteola L.). Dyes Pigment. 2003, 57, 267-272. [CrossRef]

10. Ferreira, E. New Approaches Towards the Identification of Yellow Dyes in Ancient Textiles. Ph.D. Thesis, University of Edinburgh, Edinburgh, Scotland, 2002.

11. Amat, A.; Clementi, C.; Miliani, C.; Romani, A. Complexation of apigenin and luteolin in weld lake: A DFT/TDDFT investigation. Phys. Chem. 2010, 12, 6672-6684. [CrossRef] [PubMed]

12. Dong, H.; Yang, X.; He, J.; Cai, S.; Xiao, K.; Zhu, L. Enhanced antioxidant activity, antibacterial activity and hypoglycemic effect of luteolin by complexation with manganese (II) and its inhibition kinetics on xanthine oxidase. RSC Adv. 2017, 7, 53385-53395. [CrossRef]

13. Gao, L.G.; Wang, H.; Song, X.L.; Cao, W. Research on the chelation between luteolin and Cr (III) ion through infrared spectroscopy, UV-vis spectrum and theoretical calculations. J. Mol. Struct. 2013, 1034, 386-391. [CrossRef]

14. Smith, G.J.; Thomsen, S.J.; Markham, K.R.; Andary, C.; Cardon, D. The photostabilities of naturally occurring 5-hydroxyflavones, flavonols, their glycosides and their aluminium complexes. J. Photoch. Photobio. A 2000, 136, 87-91. [CrossRef]

15. Castro, R.; Miranda, A.; Melo, M.J. Interpreting lac dye in medieval written sources: New knowledge from the reconstruction of recipes relating to illuminations in Portuguese manuscripts. In Sources in Art Technology: Back to Basics; Clarke, M., Townsend, J., Stijnman, A., Eds.; Archetype Publications: London, UK, 2016; pp. 88-99.

16. Vitorino, T.; Melo, M.J.; Carlyle, L.; Otero, V. New insights into brazilwood manufacture through the use of historically accurate reconstructions. Stud. Conserv. 2015, 61, 255-273. [CrossRef]

17. Melo, M.J.; Castro, R.; Nabais, P.; Vitorino, T. The book on how to make all the colour paints for illuminating books: Unravelling a Portuguese Hebrew illuminators' manual. Herit. Sci. 2018, 6, 44. [CrossRef]

18. Vitorino, T.; Otero, V.; Carlyle, L.; Melo, M.J.; Parola, A.J.; Picollo, M. Nineteenth-century cochineal lake pigments from Winsor \& Newton: Insight into their methodology through reconstructions. In Proceedings of the ICOM-CC 18th Triennial Conference Preprints, Copenhagen, Denmark, 4-8 September 2017; Bridgland, J., Ed.; Paper 0107.

19. Nabais, P.; Oliveira, J.; Pina, F.; Teixeira, N.; de Freitas, V.; Brás, N.F.; Clemente, A.; Rangel, M.; Silva, A.M.S.; Melo, M.J. A 1000-year-old mystery solved: Unlocking the molecular structure for the medieval blue from Chrozophora tinctoria, also known as folium. Sci. Adv. 2020, 6, eaaz7772. [CrossRef] [PubMed]

20. Clarke, M.; Carlyle, L. Page-image recipe databases, a new approach for accessing art technological manuscripts and rare printed sources: The Winsor \& Newton archive prototype. In Proceedings of the ICOM-CC 14th Triennial Meeting, The Hague, The Netherlands, 12-16 September 2005; Bridgland, J., Ed.; James \& James: London, UK, 2005; Volume 1, pp. 24-29.

21. Clarke, M.; Carlyle, L. Page-image recipe databases: A new approach to making art technological manuscripts and rare printed sources accessible. In Art of the Past-Sources and Reconstructions; Clarke, M., Townsend, J., Stijnman, A., Eds.; Archetype Publications: London, UK, 2005; pp. 49-52.

22. Carlyle, L.; Alves, P.; Otero, V.; Melo, M.J.; Vilarigues, M. A question of scale and terminology, extrapolating from past practices in commercial manufacture to current laboratory experience: The Winsor \& Newton 19th century artists' materials archive database. In Proceedings of the ICOM-CC 16th Triennial Meeting, Lisbon, Portugal, 19-23 September 2011; Bridgland, J., Ed.; Paper 0102.

23. Carlyle, L. The Artist's Assistant: Oil Painting Instruction Manuals and Handbooks in Britain, 1800-1900, with Reference to Selected Eighteenth-Century Sources; Archetype Publications: London, UK, 2001.

24. Otero, V.; Pinto, J.V.; Carlyle, L.; Vilarigues, M.; Cotte, M.; Melo, M.J. Nineteenth century chrome yellow and chrome deep from Winsor \& Newton ${ }^{\mathrm{TM}}$. Stud. Conservat. 2017, 62, 123-149.

25. Otero, V.; Campos, M.F.; Pinto, J.V.; Vilarigues, M.; Carlyle, L.; Melo, M.J. Barium, zinc \& strontium yellows in late 19th-early 20th century oil paintings. Herit. Sci. 2017, 5, 46. [CrossRef]

26. Mouri, C.; Mozaffarian, V.; Zhang, X.; Laursen, R. Characterization of flavonols in plants used for textile dyeing and the significance of flavonol conjugates. Dyes Pigment. 2014, 100, 135-141. [CrossRef]

27. Zhang, X.; Laursen, R.A. Development of mild extraction methods for the analysis of natural dyes in textiles of historical interest using LC-diode array detector-MS. Anal. Chem. 2005, 77, 2022-2025. [CrossRef] [PubMed]

28. Favaro, G.; Clementi, C.; Romani, A.; Vickackaite, V. Acidichromism and ionochromism of luteolin and apigenin, the main components of the naturally occurring yellow weld: A spectrophotometric and fluorimetric study. J. Fluoresc. 2007, 17, 707-714. [CrossRef] [PubMed]

29. Villela, A.; van der Klift, E.J.C.; Mattheussens, E.S.G.M.; Derksen, G.C.H.; Zuilhof, H.; van Beek, T.A. Fast chromatographic separation for the quantitation of the main flavone dyes in Reseda luteola (weld). J. Chromatogr. A 2011, 1218, 8544-8550. [CrossRef] [PubMed] 
30. Villela, A. Textile Dyeing with a Flavonoid Dye: Photo-Stability and Analytical Chemistry Methods. Ph.D. Thesis, Wageningen University, Wageningen, The Netherland, 2020.

31. Nakamoto, K. Infrared and Raman Spectra of Inorganic and Coordination Compounds; Wiley: Hoboken, NJ, USA, 2009.

32. Machado, N.F.L.; de Batista Carvalho, L.A.E.; Otero, J.C.; Marques, M.P.M. A conformational study of hydroxyflavones by vibrational spectroscopy coupled to DFT calculations. Spectrochim. Acta A Mol. Biomol. Spectrosc. 2013, 109, 116-124. [CrossRef] [PubMed]

33. Baranović, G.; Šegota, S. Infrared spectroscopy of flavones and flavonols. Reexamination of the hydroxyl and carbonyl vibrations in relation to the interactions of flavonoids with membrane lipids. Spectrochim. Acta A Mol. Biomol. Spectrosc. 2018, 192, 473-486. [CrossRef] [PubMed]

34. Heneczkowski, M.; Kopacz, M.; Nowak, D.; Kuzniar, A. Infrared spectrum analysis of some flavonoids. Acta Pol. Pharm. Drug Res. 2001, 58, 415-420.

35. Sanches, D.; Ramos, A.M.; Coelho, J.F.J.; Costa, C.S.M.F.; Vilarigues, M.; Melo, M.J. Correlating thermophysical properties with the molecular composition of 19th century chrome yellow oil paints. Polym. Degrad. Stab. 2017, 138, 201-211. [CrossRef] 